\title{
The Use of Time- and Chemically-Resolved Particulate Data to Characterize the Infiltration of Outdoor PM-2.5 into a Residence in the San Joaquin Valley
}

\author{
Melissa M. Lunden ${ }^{1 *}$, Tracy L. Thatcher ${ }^{1}$, Susanne V. Hering ${ }^{2}$, and Nancy J. Brown ${ }^{1}$ \\ ${ }^{1}$ Environmental Energy Technologies Division, Lawrence Berkeley National Laboratory, \\ Berkeley, California 94720 \\ ${ }^{2}$ Aerosol Dynamics Inc., 2329 Fourth Street, Berkeley, California 94710
}

\begin{abstract}
Recent studies associate particulate air pollution with adverse health effects. The indoor exposure to particles of outdoor origin is not well characterized, particularly for individual chemical species. In response to this, a field study in an unoccupied, singlestory residence in Clovis, California was conducted. Real-time particle monitors were used both outdoors and indoors to quantity PM2.5 nitrate, sulfate, and carbon. The aggregate of the highly time-resolved sulfate data, as well as averages of these data, was fit using a time-averaged form of the infiltration equation, resulting in reasonable values for the penetration coefficient and deposition velocity. In contrast, individual values of the indoor/outdoor ratio can vary significantly from that predicted by the model for time scales ranging from a few minutes to several hours. Measured indoor ammonium nitrate levels were typically significantly lower than expected based solely on penetration and deposition losses. The additional reduction is due to the transformation of ammonium nitrate into ammonia and nitric acid gases indoors, which are subsequently lost by deposition and sorption to indoor surfaces. This result illustrates that exposure assessments based on total outdoor particle mass can obscure the actual causal relationships for indoor exposures to particles of outdoor origin.
\end{abstract}

\footnotetext{
"Corresponding Author. Tel: +1-510-486-4891; Fax: +1-510-486-5928;

E-mail address: MMLunden@1bl.gov; Mail stop 51R0208
} 


\section{Introduction}

The association of ambient particulate air pollution with increased morbidity and mortality has become an important focus for the air quality, health, and regulatory communities $(1,2,3,4)$. Determining the actual exposure of the population to outdoor particles measuring less than $2.5 \mu \mathrm{m}$ in diameter (PM2.5) is key to understanding this issue. Investigation of quantitative relationships between particulate-matter concentrations measured at stationary outdoor monitoring sites and the actual breathingzone exposures of individuals has been identified by the National Research Council Committee on Research Priorities for Airborne Particulate Matter as one of the ten top research priorities (5). Determining indoor concentration is particularly crucial because individuals spend, on average, about $90 \%$ of their time indoors, with $70 \%$ of that time spent in homes (6). If indoor concentrations of outdoor PM2.5 cannot be quantified, then personal exposures cannot be estimated based on outdoor monitoring sites. If exposures are not adequately characterized, then causal relationships between outdoor PM2.5 and health effects may be erroneously attributed.

Prior studies of indoor and outdoor particle concentrations have taken two forms: mechanistic and phenomenological. Mechanistic studies are designed to evaluate the relationship between indoor and outdoor concentrations based on detailed measurements made under controlled conditions, in a laboratory setting or in a single room or house $(7,8,9,10)$. These studies have provided valuable insights into mechanisms, but rely on very detailed and generally unavailable input data such as time resolved ventilation rates, size resolved particle measurements, estimates of mixing energy, and measures of leakage pathways. Phenomenological studies typically are focused to measure indoor to outdoor concentration ratios of particulate mass in a single house or a small sample of houses but without the ancillary process-related measurements that are needed to provide predictive capability $(11,12,13,14)$. Some recent field studies have combined detailed measures of particle characteristics and house environment under realistic conditions, improving predictive capability $(15,16,17,18)$. However, few studies include chemicallyresolved measurements of the primary chemical constituent of indoor and outdoor PM2.5 $(19,20)$.

This paper introduces a study designed to focus on the physicochemical processes affecting indoor/outdoor relationships for PM2.5. The ultimate objective is to develop a physically-based semiempirical model that can be used to estimate the concentration of the chemical constituents of outdoor PM2.5 in the indoor environment using outdoor 
pollutant monitoring data, meteorological data, and available data for the housing stock such as leakage rates. We use "semiempirical" in this context to mean that the mathematical form of the governing equations is consistent with the dominant physical and chemical processes, and that the model includes one or more parameters determined from experiment. The parameters may also be distributions that are sampled, using Monte Carlo methods, to provide estimates of the distributions of independent variables, e.g., concentrations of outdoor PM2.5 for houses in a region. This modeling approach is more powerful than purely empirical descriptions since it allows for significant extrapolation within the boundaries of the evaluated domain.

We conducted a well-controlled set of experiments in an unoccupied, single-story residence in Clovis, California, a suburb of Fresno, in the San Joaquin Valley. The residence was used as a laboratory to investigate the effects of changes in the indoor environment on indoor concentrations of particles of outdoor origin. The measurements provide data on indoor and outdoor concentration relationships for PM2.5 as a function of size and chemical composition under a variety of configurations of the ventilation, heating and cooling system of the house. Indoor sources were minimized to allow the quantitation of indoor concentrations of particles of outdoor origin.

A major product of this study is a rich chemically resolved near real-time data set that reflects the dynamic character of particle transport indoors. This type of data is essential to answer important questions concerning exposure and data aggregation. This paper is directed toward answering two questions: First, is chemical speciation of particle data required for determining exposure to particles of outdoor origin? Second, can we identify levels of data aggregation that are appropriate for different applications, e.g. long-term exposure to particulate matter versus individual pollutant episodes? To explore this question, data for the chemically conserved species ammonium sulfate were averaged over a number of time periods, and analyzed using a time-averaged form of the infiltration mass balance model. The parameters resulting from the analysis will be used to assess the effect of this data aggregation.

\section{Experimental Methods}

Sampling Site

The experimental research facility is a moderate-sized $\left(134 \mathrm{~m}^{2}\right)$, single-story home constructed in 1972. The structure is of wood-frame construction over a crawl space. It 
has a stucco exterior, sliding aluminum frame windows, standard height ceilings $(2.4 \mathrm{~m})$, a forced air heating and cooling system with ducts located in the attic, and ceiling fans. All the floors were carpeted, with the exception of linoleum in the kitchen and bathrooms. The residence, a rental, was in typical condition for its age. The house is located in a residential neighborhood, surrounded by mature trees and homes of a similar height and size. The flat terrain and high level of sheltering resulted in relatively low levels of wind loading near the building. Figure 1 shows a floor plan of the home.

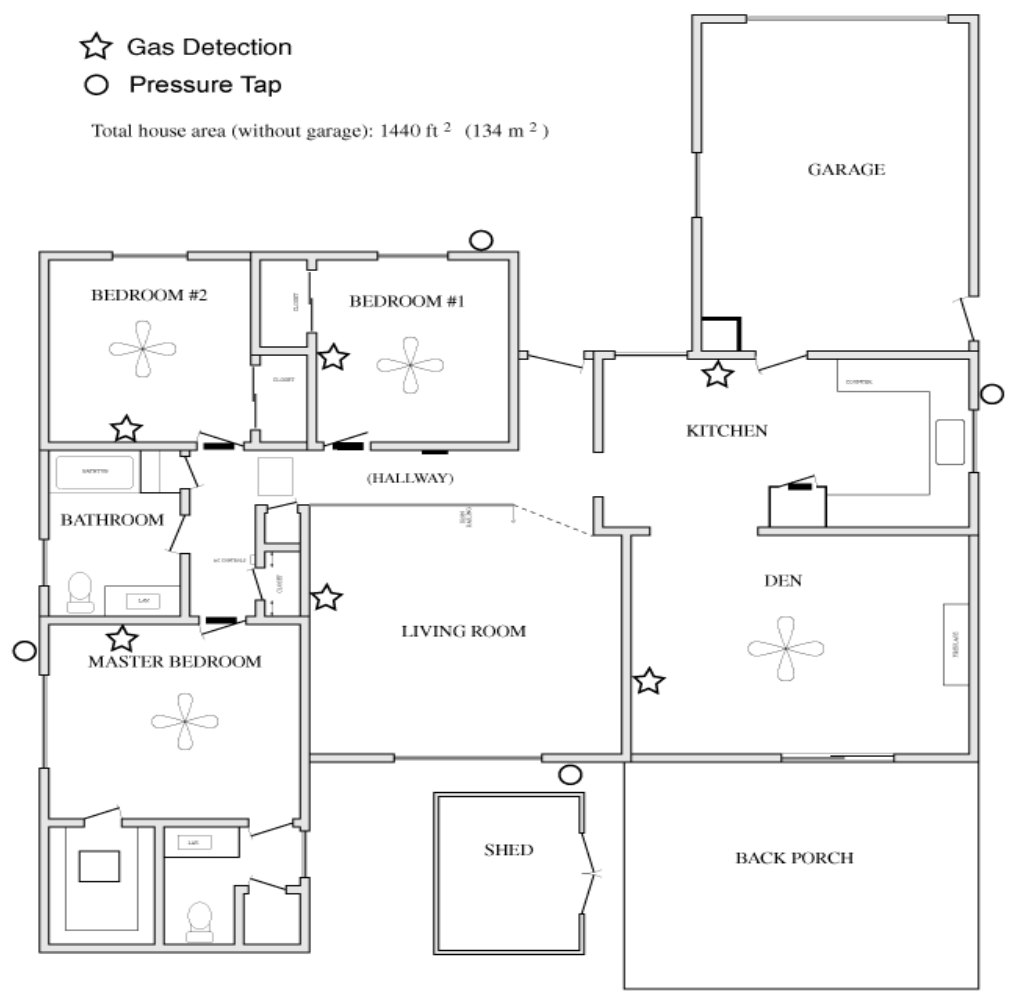

Figure 1. The floor plan of the Clovis research house. The stars denote gas sampling locations for the tracer gas system and the circles denote locations of pressure taps to measure the pressure difference across the building shell. 


\section{Sampling Periods}

Experimental measurements were conducted during two periods, from August through October 2000, and again from December 2000 through January 2001. Within these periods, several weeks were devoted to intensive measurements that included 12-hour filter-based measurements of particle chemistry, constant measurements of ventilation rates, and manual manipulation of the conditions in the house. The intensive periods were October 9-23, December 11-19, 2000 and January 16-23, 2001. During these periods, entry into the house was limited to an approximately one-hour period at midday during which instrument checks, flow calibrations, and filters changes were performed.

\section{Analytical Methods}

The physical properties of indoor and outdoor aerosols were measured simultaneously by the following instruments, operating in pairs: aerodynamic particle counters (TSI 3320) providing size distributions from 0.5 to $10 \mu \mathrm{m}$, optical particle counters (PMS LAS-X) providing size distributions from 0.1 to $3 \mu \mathrm{m}$, condensation particle counters (one TSI 3020 and one TSI 3025) providing total particle counts, and nephelometers (Radiance Research M903) providing total particle scattering. Data were collected with a time resolution of 3 minutes during the fall intensive and 5 minutes during the winter intensives. Indoor and outdoor black carbon were measured with 10-minute time resolution using a pair of aethalometers developed at Lawrence Berkeley National Laboratory (21). Replicate outdoor measurements were made during the winter with an additional Aethalometer (McGee Scientific, Berkeley, CA). The indoor particle instruments were situated in the living room of the house with the inlets placed $1 \mathrm{~m}$ above the floor and away from the walls to minimize wall disturbances. The ceiling fans were operated during the experiments to promote mixing. An additional oscillating fan located approximately $1.5 \mathrm{~m}$ from the floor was operated in the living room to promote mixing near the particle measurement equipment. The outdoor instruments and the data acquisition system were placed in a shed that was constructed in the backyard of the house. The outdoor instruments sampled through two sample lines with PM-10 inlets (Rupprecht \& Patashnick [R\&P] Co, 57-000596) located at a height of $5.5 \mathrm{~m}$, with individual instruments drawing isokinetic samples from the main flow. The outdoor nephelometer and aethalometer sample line passed through an additional PM2.5 sharp cut cyclone (R\&P 57-005896). 
PM2.5 nitrate, carbon, and sulfate were measured with 10-minute time resolution using integrated collection and vaporization cells (ICVC) (22). Particles were collected by humidification and impaction and analyzed in situ by flash-vaporization. Nitrate was measured using low-temperature vaporization in a nitrogen carrier gas with quantitation of the evolved nitrogen oxides by a chemiluminescent monitor equipped with a molybdenum converter (Thermoenvironmental 42C). Sulfate and carbon were measured from the same cell. One portion of the evolved vapors was analyzed for carbon using an $\mathrm{MnO}_{2}$ catalyst heated to $650 \mathrm{C}$ and a nondispersive infrared absorption detector for $\mathrm{CO}_{2}$ (Licor 6252), and the remainder of the evolved vapors were analyzed for sulfur dioxide by uv-fluorescence (Thermoenvironmental 43C TL). Two sets of cells were used to allow simultaneous indoor and outdoor collection. Gas analyzers and flash vaporization electronics were shared between the indoor and outdoor cells. The entire system was located in the living room of the house, but the outdoor sampling line and cells were maintained at outdoor temperature by means of a ventilated enclosure around both the sampling line and collection cells. Outdoor particles were sampled from the top of the backyard shed at a height of $4 \mathrm{~m}$. The indoor system sampled directly from the room at a height of $1.5 \mathrm{~m}, 0.6 \mathrm{~m}$ from the wall. Both systems employed a $2.5 \mu \mathrm{m}$ impactor precut. The calculated transport losses in the outdoor sampling line, which was sized to give laminar flow, were less than $2 \%$ over the size range from 0.05 to $2 \mu \mathrm{m}$.

Ammonia, nitrous acid, nitric acid and sulfur dioxide were measured using an automated on-line ion chromatograph (IC) system. The IC analysis system collects the water-soluble gases using wet denuders, followed by concentration and ion chromatographic analysis. Measurement of both anion and cation species was enabled by the use of a dual-channel IC. Denuders were located both inside and outside the house, and provided data with 30minute time resolution. More detail regarding the development, calibration, and operation of the instrument can be found in Fischer et al. (23).

Three pairs of filter samples provided 11.5 hour integrated samples of both inside and outside PM2.5 mass as well as carbon, nitrate, sulfate, and ammonium through chemical analysis. Two sets of samples were collected each day, running from midnight to 11:30AM and from 12:30PM to midnight. Computer controlled three-way solenoid vales were used to automatically switch the sample flow from one first set of filters to the second at midnight. The first sampling line used dual $25 \mathrm{~mm}$ diameter quartz filters operated in series for total and organic carbon concentrations and the organic sampling artifact $(24,25)$. The second sample line consisted of a $\mathrm{NaCl}$ coated honeycomb denuder 
followed by a $25 \mathrm{~mm}$ Teflon filter (Gelman), and then two $47 \mathrm{~mm}$ cellulose fiber filters (Whatman) in a Teflon filter holder (Savillex). The two cellulose filters were impregnated with $\mathrm{NaCl}$ and citric acid, respectively, to allow for the analysis of gaseous nitric acid and ammonia, respectively $(26,27)$. Both the carbon and denuded sample lines employed a $2.5 \mu \mathrm{m}$ cyclone precut (28). The third sample line was similar to the second, with a $25 \mathrm{~mm}$ Teflon filter followed by two impregnated $47 \mathrm{~mm}$ cellulose fiber filters but with no denuder. Instead, the Teflon filter was housed in a $25 \mathrm{~mm}$ Teflon filter holder (Savillex) with a drilled out inlet resulting in a pseudo-open faced sample. The flow rate for all sample lines was $12.5 \mathrm{~L} / \mathrm{min}$.

PM2.5 mass was gravimetrically determined using a Cahn Model 21 electro-balance. Before weighing, the Teflon filters were equilibrated for at least 4 hours at $20{ }^{\circ} \mathrm{C}$ and a relative humidity of $35 \%$. For chemical analysis, the filters were extracted by sonication in distilled deionized water. Extracts from both the denuded and open-faced Teflon filters were analyzed for nitrate and sulfate by ion chromatography and for ammonium by an ion-specific (ammonia gas-sensing) electrode and by colorimetry (phenate/indophenol method). The $\mathrm{NaCl}$ impregnated cellulose fiber filter was similarly extracted and chloride ion was removed using a cartridge containing a silver-forming cation exchange resin (Dionex OnGuard Ag), followed by a hydrogen-forming cation exchange cartridge (Dionex OnGuard H) to remove metals. The treated extract was then analyzed by ion chromatography. The citric acid impregnated cellulose fiber filters were similarly extracted and the extract analyzed for ammonium ion by an ion-specific electrode. The quartz filters were assayed for carbon using the evolved gas analysis method of Novakov et al. $(29,30)$. The ambient organic carbon particulate was calculated as the difference between the values measured on the front and back filter. The filter measurements were used to validate the data from the near real-time chemically resolved instruments.

Ventilation rates were measured using a continuous release $\mathrm{SF}_{6}$ tracer gas measurement system (Breul \& Kajer, Model 1302). Samples were taken at six locations in the house, noted in Fig. 1, at a location of $1.4 \mathrm{~m}$ above the floor with 10-minute time resolution. The time varying infiltration rate is calculated using a transient mass balance approach that accounts for the injection rate and the time dependent infiltration losses. In general, the calculated air exchange rate at a given time was essentially the same for each measurement location within the house, thus this work uses the average concentration for all locations as the air change rate. The differential pressure across the building shell was measured at an average height of $1.4 \mathrm{~m}$ on each of the four walls of the house, as shown 
in Figure 1, using an automated differential pressure measurement system (Energy Conservancy, APT system). Temperature was measured at the same location as each of the four differential pressure measurements as well as at a vent of the forced air system located in the living room. A vertical temperature profile was also measured in the living room using three sensors at approximately $0.5,1.0$, and $1.5 \mathrm{~m}$ in height. Temperature and relative humidity were measured both inside and outside the house using dual temperature and relative humidity probes (Vaisala HMD70Y) mounted in aspirated, shielded enclosures and recorded using a Cambell 23X logging system. Wind speed and wind direction were measured using a RM Young wind monitor (Model 05103) mounted to the shed in the backyard at a height of $4.1 \mathrm{~m}$.

Instrument control and data acquisition for all instruments were accomplished from the backyard shed, with the exception of the tracer gas, house temperature, and pressure systems. This allowed for minimal house entry and disturbance of the indoor environment.

\section{Quality Assurance}

Time-integrated concentrations from the ICVC measurements were compared to those obtained from the 11.5-hour filter samples for both nitrate and sulfate. For nitrate, these comparisons yield $\mathrm{R}^{2}>0.96$, with a regression slope of 1.14 , while sulfate yielded an $\mathrm{R} 2$ of 0.97 with a regression slope of 0.97 . The comparability of the indoor and outdoor cells was evaluated by sampling indoor air with both cells under high ventilation conditions. The two nitrate cells were correlated with an $\mathrm{R}^{2}=0.97$, with the indoor cell

reporting $15 \%$ lower values, on average. The two sulfate cells were correlated with an $\mathrm{R}^{2}$ $=0.85$, with the indoor cell reporting $35 \%$ lower values, on average. The precision of the nitrate and sulfate ICVC data is the greater of $0.5 \mu \mathrm{g} / \mathrm{m} 3$ or $5 \%$ and $0.5 \mu \mathrm{g} / \mathrm{m} 3$ or $8 \%$ respectively.

\section{Ventilation Conditions}

In October, most measurements were made with the house closed, and with ventilation controlled by the natural driving conditions of wind loading and temperature gradients across the building shell. Under these naturally occurring conditions, the house displayed a relatively limited range of ventilation rates, which varied from 0.2 to 0.5 air changes per 
hour $(\mathrm{ACH})$, only rising appreciably when the doors and/or windows were opened. The normalized leakage area of the house, as measured with a blower door, is 0.65 (31).

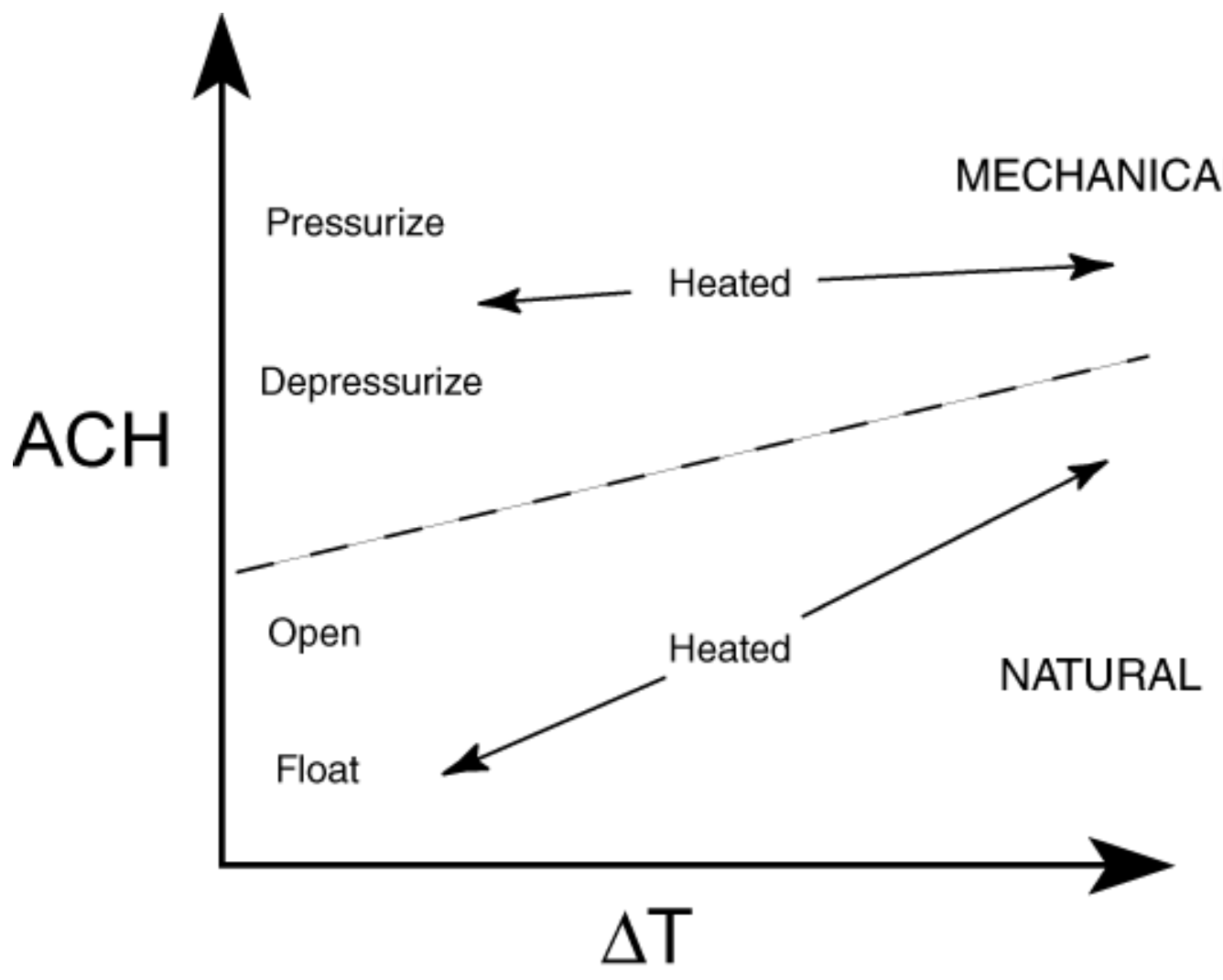

Figure 2. A schematic of the range of infiltration rates $(\mathrm{ACH})$ and indoor/outdoor temperature differences that we explored during the winter intensives. The boundary between "forced" and "natural" demarks higher values of ACH that could only be achieved by mechanical means. See the text for a description of the terms used to describe different conditions.

To explore the range of ventilation rates that occur in homes, we used a number of different techniques to manipulate both the ventilation rate and the temperature gradient, using the house as a laboratory to explore the range of conditions illustrated in Fig. 2. This diagram graphically depicts the parameter space of house operating conditions and provides labels that summarize the techniques used to extend the parameter space to enable experimentation at conditions representative of a larger sample of the housing stock. The term "float" refers to a closed house with no additional forcing factors. A house with open doors or windows is termed "open." To move from naturally produced infiltration conditions to larger values for $\mathrm{ACH}$ required forcing additional air into the 
house by mechanical means. We utilized two methods to increase the ventilation rate beyond that normally experienced by this house. The first method made use of the fan over the kitchen range to depressurize the building interior and increase the ventilation rate to values between 1 and $2 \mathrm{ACH}$. The second method involved the use of a fan mounted in the master bedroom window. This fan pressurized the house resulting in ventilation rates of 4 to $6 \mathrm{ACH}$. These large ventilation rates enabled experimental investigation of conditions where the time scales for infiltration were very fast relative to the other important time scales in the house. This proved particularly important for observing the indoor nitrate chemistry. The indoor temperature was controlled with the house heating system using three nominal settings - no heat, a lower heating setting 20 ${ }^{\circ} \mathrm{C}\left(68^{\circ} \mathrm{F}\right)$, and a higher heating setting of $26^{\circ} \mathrm{C}\left(78^{\circ} \mathrm{F}\right)$. The system could also be adjusted to conditions of either no or continual heating system fan operation. A listing of the house conditions explored during the December intensive period is shown in Table I. The conditions listed as AM and PM corresponded with the two filter measurement periods.

Table I: Conditions used to simulate different driving forces on the house during the December 2000 intensive measurement period. For a detailed discussion of the terms see the text.

\begin{tabular}{|l|l|l|l|l|}
\hline \multirow{2}{*}{ Date } & \multicolumn{2}{|c|}{ AM } & \multicolumn{2}{c|}{ PM } \\
\cline { 2 - 5 } & Ventilation & Temperature & \multicolumn{1}{c|}{ Ventilation } & Temperature \\
\hline Dec 11 & & & Float & No heat \\
\hline Dec 12 & Float & No heat & Open & No heat \\
\hline Dec 13 & Float & Heat 68F & Depressurize & Heat 68F \\
\hline Dec 14 & Pressurize & Heat 68F & Float & Heat 78F \\
\hline Dec 15 & Float & Heat 78F & Depressurize & No heat, \\
\hline Dec 16 & Depressurize & No heat & Pressurize & Heat 68F \\
\hline Dec 17 & Depressurize & Heat 68F & Float & No heat \\
\hline Dec 18 & Float & No heat & Pressurize & Heat 68F \\
\hline Dec 19 & Pressurize & Heat 68F & & \\
\hline
\end{tabular}




\section{Results and Discussion}

Figure 3 presents results from the ICVC system illustrating the variation in indoor and outdoor nitrate, sulfate and total carbon for a four-day period during the December intensive. Fig. 3 also shows the ventilation rate, indicated as air changes per hour ( $\mathrm{ACH})$, during the same period. High air change rates measured from noon to midnight on December $16^{\text {th }}$ and from noon on December $18^{\text {th }}$ until noon on December $19^{\text {th }}$ reflect the use of mechanical ventilation. The results show considerable variability in both the indoor and outdoor concentrations of all three species, as well as the magnitude of the difference between the indoor and outdoor concentrations. As would be expected, the difference between the indoor and outdoor concentration generally decreases appreciably during periods of high air change rate. At these high ventilation rates, the characteristic time for particle gain by ventilation is significantly less than that for loss by deposition. Figure 3 also shows that individual chemical constituents of PM2.5 behave differently upon entrance into the residence. The difference between indoor and outdoor nitrate concentrations is much greater than the difference measured for either sulfate or carbon despite expected similarities in particle size ranges. Ammonium nitrate is a chemically active species that exists in equilibrium with gaseous nitric acid and ammonia. The equilibrium is strongly influenced by temperature, which usually differs from outside to inside.

\section{Indoor Concentration of Outdoor Particles}

A mass balance model describing the time rate of change of indoor particulate concentration $\mathrm{C}_{\mathrm{I} ; \mathrm{i}, \mathrm{j}}\left(\right.$ in $\# / \mathrm{cm}^{3}$ ) of species $\mathrm{i}$ and aerodynamic size $\mathrm{j}$, can be written as $(7,11,19)$

$$
\begin{aligned}
\frac{d C_{I ; i, j}}{d t}= & C_{O ; i, j} P(j) \lambda-C_{I ; i, j}\left(\lambda \stackrel{2}{+} k_{d e p}(j)\right)+S\left(i, j, T, R H, \stackrel{3}{x_{i}}, C_{I ; i, j}, C_{O ; i, j}\right) \\
& +F\left(\underset{4}{i, j, T}, R H, x_{i}\right)+K \underset{5}{\left.j_{1}, j_{2}\right)}+H(\underset{6}{i, j, R H})
\end{aligned}
$$

Terms 1 and 2 of Eq. 1 describe the ventilation driven inflow and outflow of particles, respectively, where $C_{0 ; i, j}\left(\# / \mathrm{cm}^{3}\right)$ is the outdoor particulate concentration, and $\lambda\left(\mathrm{h}^{-1}\right)$ is the ventilation rate. $\mathrm{P}$, the penetration factor and $\mathrm{k}_{\mathrm{dep}}\left(\mathrm{h}^{-1}\right)$, the deposition loss rate, are both functions of particle size. Term 3 of Eq. 1 corresponds to a phase change, S, between the aerosol and gas phase species that occurs due to differences between the indoor and outdoor environments. It can be a complex function of particle size, species, temperature, T, relative humidity, RH, gas phase concentrations, $x_{\mathrm{i}}$, and particle 
concentration. The fourth term, F, is a chemical source term expressing the formation of new particulate material by nucleation due to the presence of gases within the house. The fifth term describes particle size change, $\mathrm{K}$, due to coagulation, and the sixth term, $\mathrm{H}$, characterizes particle size changes due to water vapor sorption. This equation assumes that other indoor sources, such as generation or resuspension, are negligible and that there is no internal filtration.

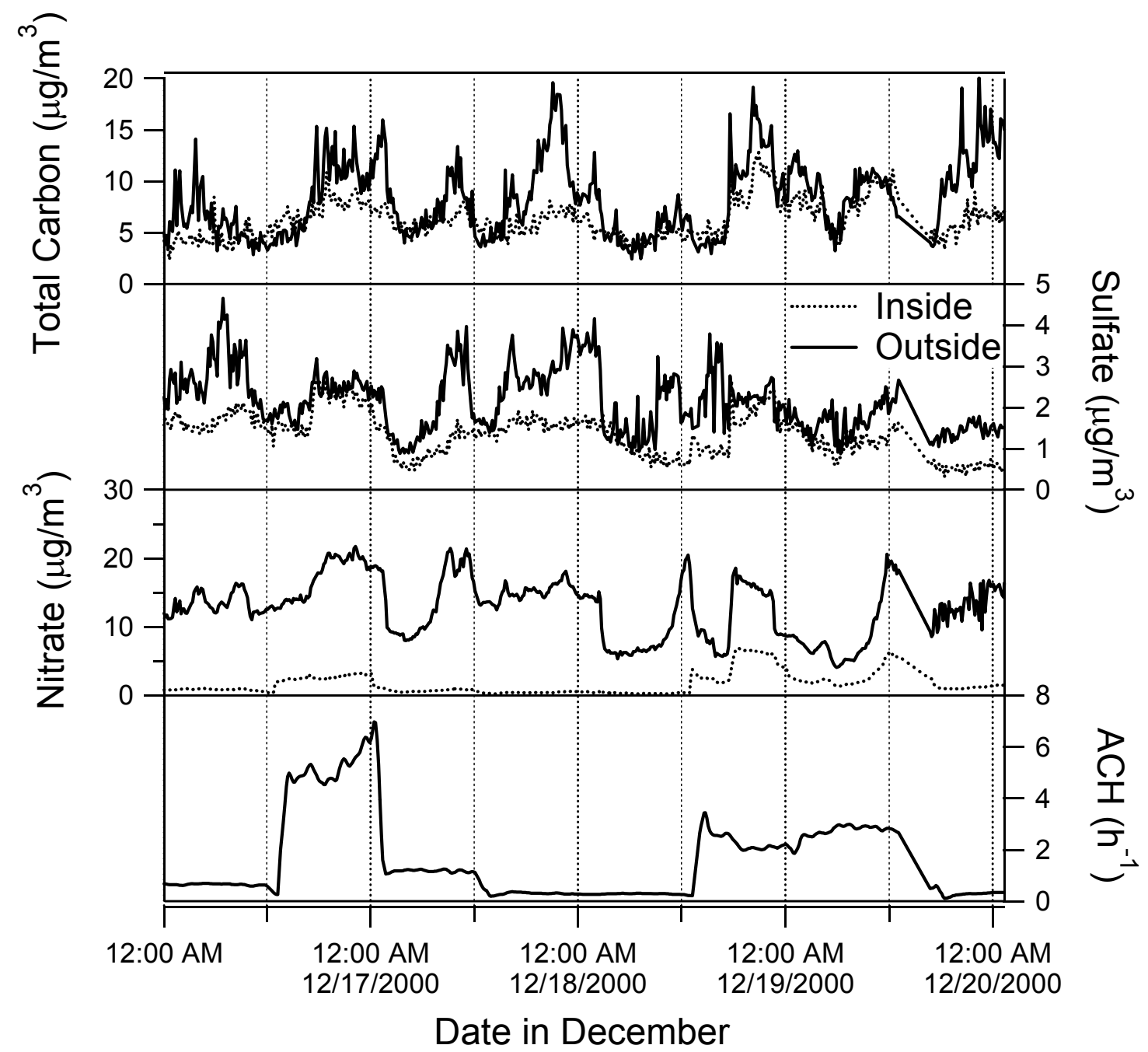

Figure 3. Data from the ICVS showing the variation in indoor (solid line) and outdoor (dotted line) carbon, sulfate, and nitrate for a four-day period during the December intensive. The bottom plot shows air exchange rate as a function of time and reflects the effects of the manipulation of the house conditions. 
It is illustrative to examine Eq. 1 as it applies to the time-resolved chemically speciated particulate measurements shown in Fig. 3. The data collected by the ICVC system are integrated over particle size, including all particles $2.5 \mu \mathrm{m}$ and smaller. For this reason, terms 5 and 6 in Eq. (1) can be neglected because coagulation or size changes due to water adsorption are not likely to move these particles out of the range of measurement. The consideration of the other terms in Eq. 1, particularly the terms concerning chemical interactions between gases and particles, will need to be viewed on a species by species basis.

We begin by applying Eq. 1. to ammonium sulfate aerosols. Ammonium sulfate is considered not to be chemically reactive once it is in particle form (33); hence, it is stable upon transport to the indoors and term 3, describing phase change, can be neglected. Although it cannot be stated with absolute certainty, we do not expect any significant nucleation of ammonium sulfate particulate inside the house due to low $\mathrm{SO}_{2}$, oxidant, and $\mathrm{H}_{2} \mathrm{O}$ levels inside the house, indicating that term 4 of Eq. 1 can also be neglected. With these simplifications, the rate of change of indoor sulfate with respect to time can be reduced to

$$
\frac{d C_{I}}{d t}=C_{O} \hat{P} \lambda-C_{I}\left(\hat{k}_{d e p}+\lambda\right),
$$

where $\hat{P}$ and $\hat{k}_{\text {dep }}$ both reduce to a single value representative of the mass median diameter for sulfate.

Most research concerning particle infiltration has utilized time integrated techniques such as filter measurements; however, Eq. 2 describes nearly instantaneous measurements. Application to such data sets requires that Eq. 2 be integrated, resulting in the following time averaged form $(34,35)$,

$$
\Delta C_{I}=\left[\overline{C_{O}} \hat{P} \lambda-\overline{C_{I}}\left(\lambda+\hat{k}_{\text {dep }}\right)\right] t_{s}
$$

where $\overline{C_{I}}$ and $\overline{C_{O}}$ are the average indoor and outdoor concentrations, respectively, over the time interval $\mathrm{t}_{\mathrm{s}}$, and $\Delta \mathrm{C}_{\mathrm{I}}$ is the change in indoor concentration over the same time interval. An important assumption when integrating Eq. 2 is that $P, \mathrm{k}_{\mathrm{dep}}$, and $\lambda$ are constant over the interval considered. Eq. 3 can be rearranged to express the ratio of the averaged indoor to outdoor concentrations,

$$
\frac{\overline{C_{I}}}{\overline{C_{O}}}=\frac{\hat{P} \lambda}{\left(\lambda+\hat{k}_{\text {dep }}\right)}-\frac{\Delta C_{I}}{\overline{C_{O}}\left(\lambda+\hat{k}_{\text {dep }}\right) t_{s}} .
$$


It is tempting to infer that the first term on the right hand side (RHS) of Eq. 4 is identical to the value of the indoor/outdoor concentration ratio obtained assuming steady-state conditions, which require that $\mathrm{dC}_{\mathrm{I}} / \mathrm{dt}=0$; however, there is an important difference. The concentrations on the left hand side of Eq. 4 are time averaged, not instantaneous values, thus the values of the variables in the first term on the RHS of Eq. 4 are representative of the average behavior of the system for a particular period of time. For this paper, we will refer to second term on the RHS as the dynamic term. For our experiment with no indoor sources, this term describes how the average indoor concentration responds to changes in the average outdoor concentration. When the averaging period, $t_{s}$, is longer than the characteristic times associated with ventilation and deposition, we would expect the magnitude of this term to be much smaller than the first term on the RHS of Eq. 4. Under these conditions, Eq. 4 will give a fixed value of the indoor/outdoor concentration ratio for a single air change rate and the ratio will depend upon the values of $\hat{P}$ and $\hat{k}_{d e p}$. It is important to note that the importance of the dynamic term is highly dependent upon the averaging time period, as averaging tends to obscure information on the dynamic response of the system.

Our current analysis of the relationship between indoor and outdoor particle concentrations is focused on the aggregate behavior of the entire data set. This analysis results in conclusions about the average particle infiltration behavior over a number of months, which is important for characterizing exposure. The data were averaged over a number of time periods to investigate how the sampling time affects data interpretation, particularly with regard to the interaction among the characteristic times associated with the significant physical processes in the system. Averaging time is especially important for the dynamic term in Eq. 4; because the magnitude of $\Delta C_{I} / \overline{C_{O}} t_{s}$ contained in this term will decrease at longer averaging times. The time period over which the highly time resolved data are averaged is equivalent to the sampling time associated with integrated measurements. Most exposure studies require sampling a large representative population. The measurements (samples) are most frequently time-integrated because large-scale deployment of highly time resolved sampling equipment has not been practical. Hence it is important to determine the effect of sampling time on exposure predictions for different types of pollutant events. There is also a relationship between sampling time and data analysis, which must be understood for dynamics to be properly interpreted. 

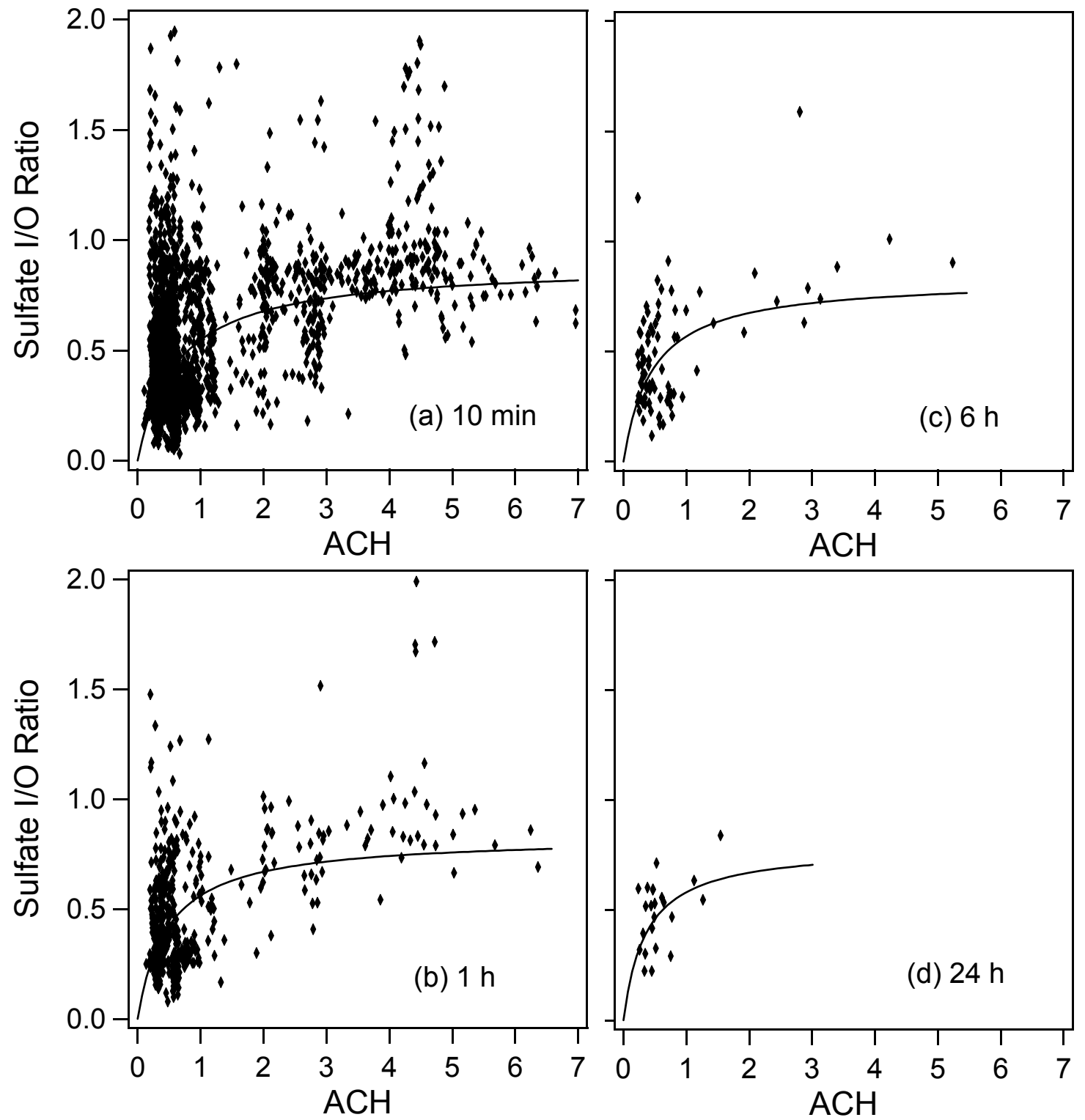

Figure 4. Sulfate indoor/outdoor ratio as measured by the ICVC system as a function of air change. The plots show the data as measured by the instrument with 10 minute resolution as well as 6- and 24- hour averaged data. The solid line is the result of the fit of Eq. 4 to the data. 


\section{Ammonium Sulfate}

The ratio of the indoor to outdoor concentrations of particulate sulfate (ammonium sulfate) measured by the ICVC system are shown in Fig. 4 as a function of average ventilation rate, indicated by air changes per hour $(\mathrm{ACH})$. The figure includes data collected during both the fall and winter intensive measurement periods. Due to difficulties with the outdoor ICVC unit, no reliable sulfate data were available after December 22, 2000. The four plots in the figure show the sulfate ratio measured every 10 minutes, as well as ratios calculated for 1-, 6- and 24-hour averages of the indoor and outdoor concentrations. A corresponding averaged air change rate was calculated for the same time span. The air change rates were averaged using a harmonic mean rather than an arithmetic mean. For the 10-minute data, a large range of indoor/outdoor ratios exists for any single value of the air change rate. The majority of points lie below 1.0, signifying that indoor concentrations are typically less than outdoors, an expected result due to the influence of penetration and deposition losses. There are, however, a significant number of points above 1.0. When the data are averaged over 6 hours, the spread in the values of the indoor/outdoor ratio is greatly reduced, and the number of values of the ratio in excess of 1.0 decreases markedly.

The shape of the distribution of the indoor/outdoor ratio data in Fig. 4 reflects the interactions between the different physical processes, each with its own characteristic time, that govern particle infiltration. The 10-minute data displayed in Fig. 4 show a large range of values for the indoor/outdoor ratio at low air change rates, with this range narrowing as ventilation rate increases. At low air change rates, the indoor concentrations do not respond quickly to changes in outdoor levels, which can result in ratios significantly greater than unity when the outdoor concentration decreases quickly, or significantly smaller than unity when the outdoor concentrations rapidly increase. These extreme values of the indoor/outdoor ratio tend to occur when the overall particle concentrations are low. As the ventilation rate increases, the indoor concentrations respond more rapidly to changes in outdoor concentrations and losses by deposition decrease in relative importance. These two factors combine to restrict the range of indoor/outdoor ratios. At large ventilation rates, the loss of particles due to deposition can be neglected, yielding the limiting case of an indoor/outdoor ratio that is equivalent to the penetration factor. 
Equation 4 was fit to the aggregated data set containing all measurement periods, weighted by the experimentally determined uncertainty of $\mathrm{C}_{\mathrm{I}}$ at each data point. The value of $\Delta C_{I} / t_{s}$ was calculated directly from the indoor concentration data using a 5point linear fit except for the 10-minute data where a 7-point fit was used. The use of multiple points was necessary to derive a meaningful value for the slope of $\mathrm{C}_{\mathrm{I}}$ that was less sensitive to measurement noise in the data. The result of the fit to Eq. 4 yields penetration coefficients and deposition velocities that approximate the averaged values under the various house conditions and particle characteristics present in the aggregated data. These values are used to assess the reasonableness of the fit. It is important to note that they are not intended to be equivalent to the size dependent penetration and deposition coefficients that are obtained through experiments designed specifically to assess their values (35). The actual deposition and penetration coefficients vary over time according to changing indoor and outdoor conditions. In addition, the first term on the RHS of Eq. 4

$$
\frac{\overline{C_{I}}}{\overline{C_{O}}}=\frac{\hat{P} \lambda}{\left(\lambda+\hat{k}_{d e p}\right)}
$$

will also be fit to the data set to assess the differences that arise between a full dynamic treatment of the data and that which arises assuming $\Delta C_{I} / \overline{C_{O}} t_{s}$ is negligible relative to the first term. We calculate the value of $\Delta C_{I} / \overline{C_{O}} t_{s}$ from the data, and compare its magnitude to $\hat{P} \lambda$ to assess the importance of the "dynamic" term for different averaging periods.

Table II lists the values resulting from the fit of Eqs. 4 and 4(a) to the sulfate data for a number of averaging periods. In addition, the table shows the statistical fit parameter $\mathrm{F}$, a modified F-statistic that quantifies an aspect of how well the model fits the data: F compares the chi-squared value achieved by the fit with the value that would be expected if the data values were randomly distributed about their mean values. The larger the value of $\mathrm{F}$, the better the fit from the proposed model compared to the assumption of random distribution about the mean. The F-statistic is itself derived from the data, and thus is subject to random variation. The statistic $\mathrm{p}$ (not shown in the table) is the probability that the observed value of $\mathrm{F}$ could be observed due to random chance; that is, if the proposed model were fit to randomly generated data, what is the chance that the fit would be at least as good as the observed fit to actual data? A small value of p suggests that the apparent fit of a model is unlikely to be accidental; often, $p<0.05$ is taken to 
indicate that the model fit is "significantly significant". In our case, all of the p-values are much less than 0.05 .

Table II: Results of the fit of Eq. 3 to the sulfate data from the ICVC system. The datasets shown are fits to all of the 10-minute data and the data averaged over a number of different averaging times. $\mathrm{N}$ is the number of data points used in the fit. For a discussion of the statistical fit parameter $\mathrm{F}$ see the text.

\begin{tabular}{|l|l|lll|lll|}
\hline \multirow{2}{*}{ Dataset } & \multirow{2}{*}{$\mathrm{N}$} & \multicolumn{3}{|c|}{ With dynamic term } & \multicolumn{3}{c|}{ Without dynamic term } \\
\cline { 3 - 8 } & & $\hat{P}_{\text {fit }}$ & $\hat{k}_{\text {dep. fit }}$ & $\mathrm{F}$ & $\hat{P}_{\text {fit }}$ & $\hat{k}_{\text {dep,fit }}$ & $\mathrm{F}$ \\
\hline $10 \mathrm{~min}$ & 4457 & 0.89 & 0.63 & 2489 & 0.82 & 0.51 & 2507 \\
$20 \mathrm{~min}$ & 1119 & 0.86 & 0.57 & 1537 & 0.82 & 0.49 & 1490 \\
$30 \mathrm{~min}$ & 873 & 0.84 & 0.52 & 1094 & 0.82 & 0.50 & 1032 \\
$1 \mathrm{hr}$ & 460 & 0.83 & 0.48 & 561 & 0.82 & 0.49 & 526 \\
$3 \mathrm{hr}$ & 162 & 0.82 & 0.46 & 156 & 0.83 & 0.48 & 150 \\
$6 \mathrm{hr}$ & 84 & - & - & - & 0.83 & 0.46 & 71 \\
$12 \mathrm{hr}$ & 42 & - & - & - & 0.78 & 0.37 & 39 \\
$24 \mathrm{hr}$ & 23 & - & - & - & 0.79 & 0.36 & 31 \\
\hline
\end{tabular}

The values of $\hat{P}_{f i t}$ and $\hat{k}_{d e p, f i t}$ resulting from the fit of Eq. 4 to the data lie in a reasonable range based on literature values $(14,15,18)$. In addition, the values of these two parameters were separately determined for the same research house, with the penetration coefficient ranging from 0.7 to 0.9 and the deposition velocity ranging from 0.2 to $0.4 \mathrm{~h}^{-1}$ for typical sulfate aerosol size ranges (in 35). The values of both the penetration factor and the deposition loss rate decrease as the averaging time is increased. Curves based on a simplified form of Eq. 4(a) using the fitted values of $\hat{P}_{f i t}$ and $\hat{k}_{\text {dep,fit }}$ are shown with the data in Fig. 4 to aid in understanding the general system behavior. The curves do appear to lie below some of the values at high air exchange rate. The data points at smaller values of sulfate I/O ratio tend to have lower uncertainty, and thus have a larger affect on the fit. The fitted value of the penetration coefficient is affected most by the values of the data at high air change rate, where deposition losses are negligible. The degree of curvature in the fit at low air change rates largely depends upon the deposition loss rate. The data at higher time resolution have a significant number of points where the ratio of indoor to outdoor sulfate concentrations are larger than one, which will tend to increase both the penetration coefficient (the position at which the curve flattens) and the deposition velocity (the curvature required to force the fit through zero indoor/outdoor 
ratio at zero air change rate). As the data is averaged over longer time periods, the number of these points is decreased, therefore the values of $\hat{P}_{f i t}$ and $\hat{k}_{d e p, \text { fit }}$ decrease.

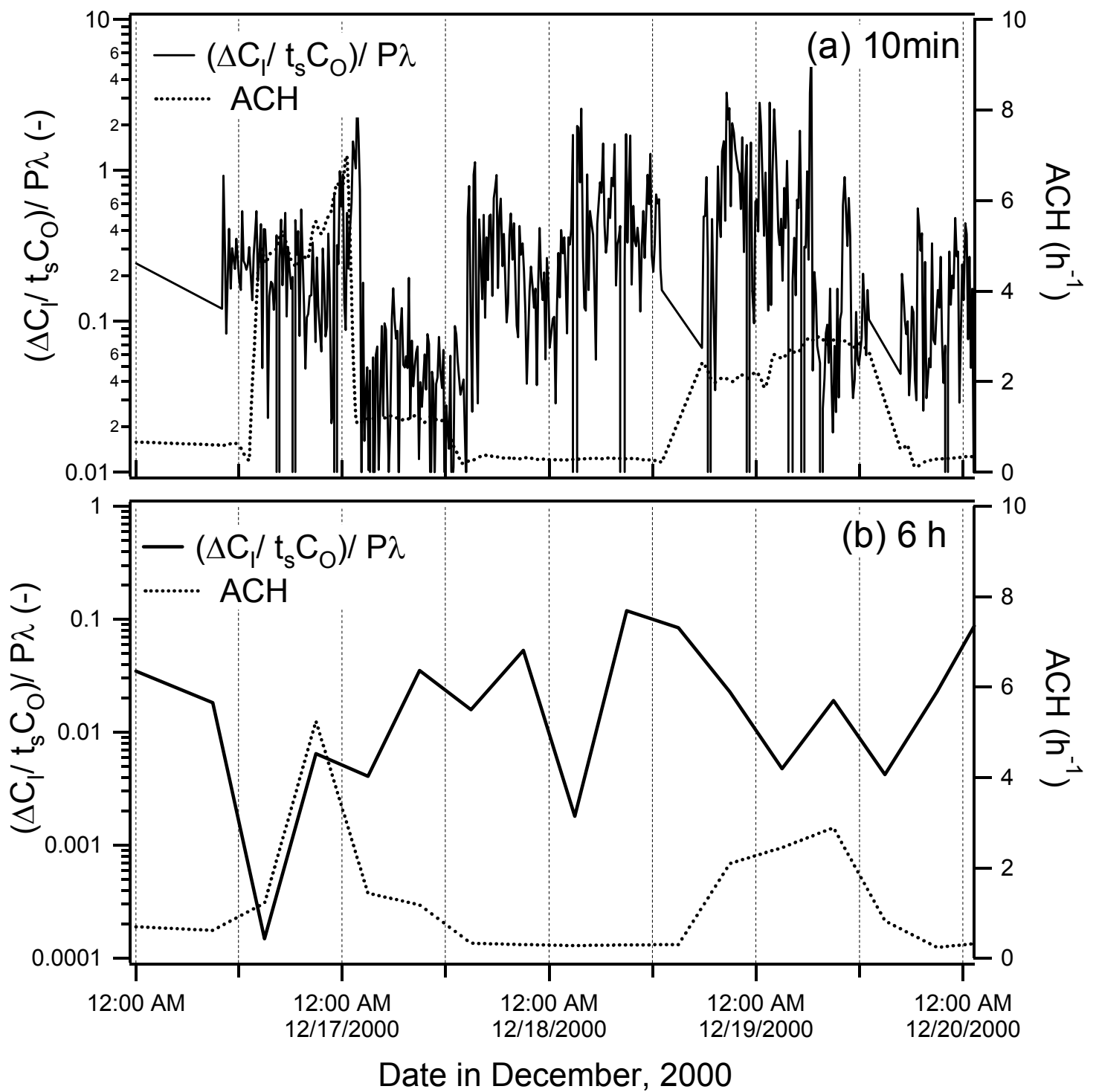

Figure 5. Results of the ratio between the absolute value of $\Delta C_{I} / \overline{C_{O}} t_{s}$ and $\hat{P} \lambda$ calculated from the sulfate data as a function of time. The air change rate as a function of time is also displayed. Figure (a) shows the results for the 10 minute data and Figure (b) for the data averaged over 6 hours. 
The values of the fit of Eq. 4 converge with the simplified form of Eq. 4(a) at an averaging period somewhere between 1 and 3 hours, and remain basically equivalent for all larger averaging periods. This implies that the value of $\Delta C_{I} / \overline{C_{O}} t_{s}$ at these averaging times is much smaller that the value of $\hat{P} \lambda$. To further investigate this condition, the ratio of these two terms of the RHS of Eq. (4) was calculated from the sulfate data. The results are shown in Fig. 5 for a time period in December, along with the air change rate. The value of $\Delta C_{I} / \bar{C}_{O} t_{s}$ is presented as an absolute value for clarity, as the sign of the term is not important in evaluating its size in comparison to $\hat{P} \lambda$. A penetration factor of 0.95 was used for this calculation based on a forward marching fit of the sulfate data using the time-dependent physical mass balance model (36). Figure 5a shows that the value $\Delta C_{I} / \overline{C_{O}} t_{s}$ is significant for the 10-minute data, with some exceptions noted for periods having high air change rates. This result is expected, since during periods of low ventilation rates a significant time lag exists between changes in the outdoor and indoor concentrations. As the data are averaged over longer periods, as shown in Fig. 5b for 6hour averages, $\Delta C_{I} / \overline{C_{O}} t_{s}$ becomes much smaller relative to $\hat{P} \lambda$ and can be neglected. From our data, for averaging periods greater than 3 hours, this dynamic term is usually less that 0.1 and can be neglected, which is also affirmed by the agreement between the fits of Eqs. 4 and 4(a).

It is interesting to note that values resulting from the fits both including and excluding the dynamic term are not very different from one another. The values resulting from the fits to the full dynamic equation are higher than those resulting from the simple form; thus, the loss of the dynamic term

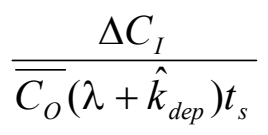

are affecting this fit by lowering the apparent penetration coefficient. The data show that the majority of the data points at values of the indoor/outdoor ratio greater than one have a negative value for the dynamic term in Eq. 5, which increases the penetration coefficient fit. The values calculated from Eq. 5 are equally distributed about zero, and their net effect on the fit of Eq. 4 results in physically realistic values that are not significantly different than those resulting from Eq. 4(a). This result provides insight into the nature of the dynamic response of the residence. The time dependent physical mass balance model, Eq. 2, states that the indoor concentration is constantly moving to adjust to the changes in outdoor concentrations. The response of the indoor concentrations is an exponential that depends upon the values of the air change rate and deposition velocity. 
Our experimental measurement of the indoor/outdoor ratio sampled the response of the indoor concentration at different stages of the exponential response. The central limit theorem states that sufficiently random sampling of this response will result in a Normal distribution of the term shown in Eq. 5. The central limit theorem also states that mean of the distribution tends toward the average of the measurements. Since the mean of the distribution in this case is zero, this implies that the values calculated from Eq. 5 are equally distributed about the value predicted by the simplified form of the time averaged mass balance equation, Eq. 4(a). This implies that the result of reasonable fits to the high-resolution indoor/outdoor data by the simplified form of Eq. 4(a) is due to the nature of the fluctuations of the system about the value predicted by time averaged model.

The results shown in Table II illustrate that all of the fits are equally statistically significant, and there is certainly no reason to believe that any particular set of values of $\hat{P}_{f i t}$ and $\hat{k}_{d e p, f i t}$ is any more physically accurate than another. Many studies use similar analyses to determine $\hat{P}_{f i t}$ and $\hat{k}_{d e p, f i t}$ from time-integrated data sets; hence, it is illustrative to comment on how the values change as a function of data aggregation. The results for averaging times up to 6 hours would result in similar predicted values of the indoor/outdoor ratio. In contrast, the penetration coefficients and deposition loss factors fitted to data averaged at 12- and 24- hours are smaller than the values resulting from shorter averaging periods. As a result, the indoor/outdoor ratio predicted from these values would be smaller than for data with higher time resolution. It is not obvious why the results from the longer time averaged data are lower. One reason may be that averaging over longer time periods reduces the range of values of the air change. As stated previously, the fitted value of the penetration coefficient is highly dependent upon the values for the indoor and outdoor concentrations at high air change rates, thus decreasing the dynamic range in the data may serve to decrease the fitted value of $\hat{P}_{f i t}$. Notably, the average value of the indoor/outdoor ratio also decreases as the data are averaged in time, which correlates with the decrease in the fit parameters. We postulate that the decrease in fitted values for the penetration coefficient and deposition velocities are due to non-linearities that affect the process of data averaging, and we currently can only speculate regarding their origin. 


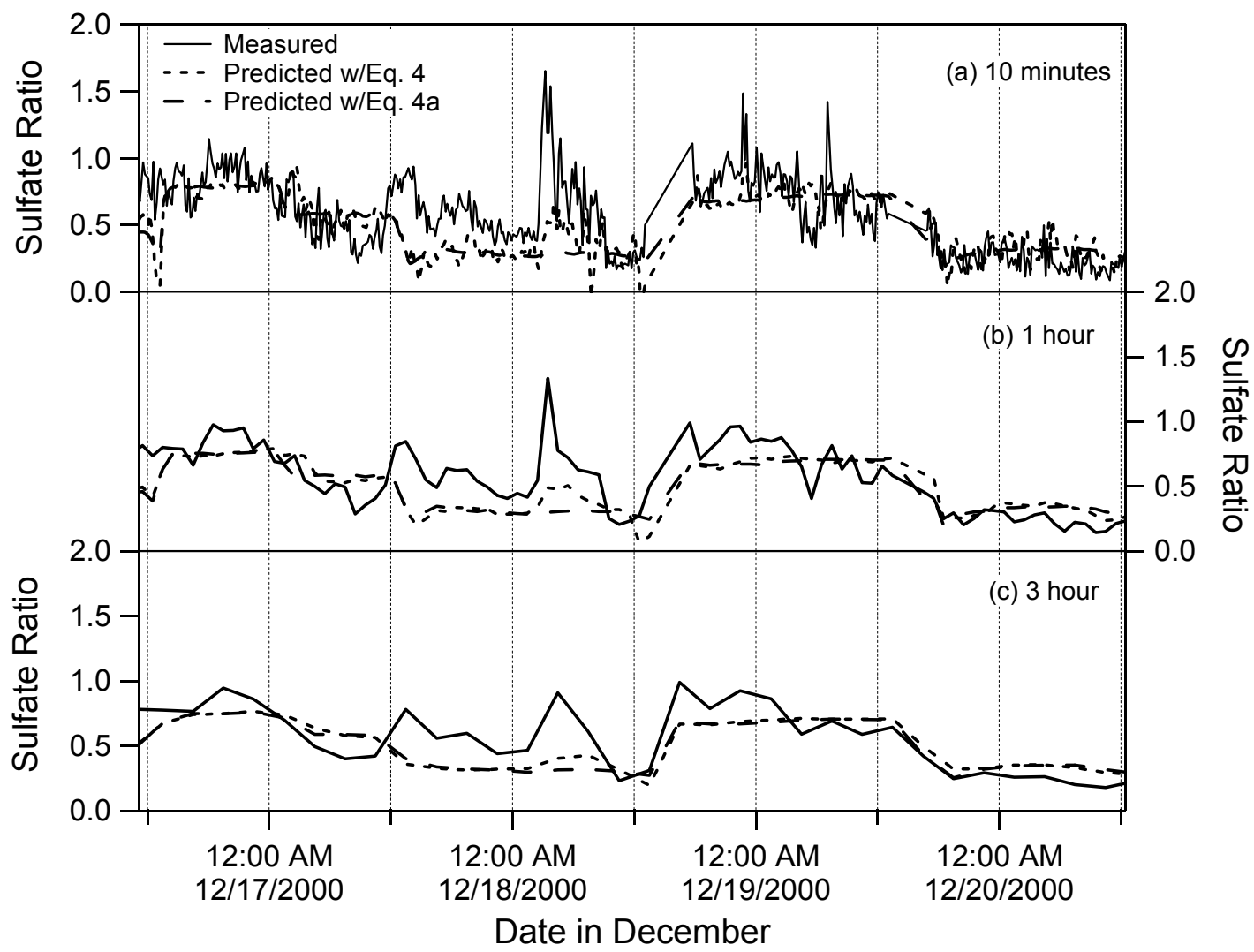

Figure 6. A comparison of the sulfate indoor/outdoor ratio measured (solid line) in the house versus that calculated from Eq. 4(short dashed line) and Eq. 4(a) (long dashed line) using the measured air change rate, and the fitted values of $\mathrm{P}_{\text {fit }}$ and $\mathrm{k}_{\mathrm{dep}, \text { fit }}$ shown in Table II.

While it is true that both the dynamic and simple forms of Eq. 4 result in reasonable fits for the penetration and deposition coefficient for the aggregate of the sulfate data set, that does not mean that Eq. 4 can be used to predict the indoor/outdoor concentration at any given time. This is illustrated in Fig. 6, which shows the measured indoor/outdoor ratio for a time period in December as well as the ratio predicted by both Eq. 4 and Eq. 4(a) for the 10-minute, 1 - and 3 - hour averaged data. The predicted values are calculated using the measured outdoor sulfate concentrations, the measured air change ratio, the calculated value of $\Delta C_{I} / t_{s}$, and the values of $\mathrm{P}_{\text {fit }}$ and $\mathrm{k}_{\mathrm{dep} \text {,fit }}$ shown in Table II. It is clear from Fig. 6 that the predicted values of the indoor/outdoor ratio using both Eqs. 4 and 4(a) are similar. For the 10-minute data, the model predictions using the full dynamic equation provide a better estimation of the dynamic behavior of the ratio, with time resolved 
increases and decreases in the indoor/outdoor ratio that better match the measured values. For the data averaged for 1- and 3-hours the predictions from the dynamic form of the equation only vary from those using the simplified form during periods where the indoor/outdoor ratio increases or decreases rapidly. Regardless of how the model results reproduce the trends of the measured data, the predictions can vary considerably for any individual measurement. For the 24-hour averaged data, the predicted and measured data do not differ as much, due to a much-reduced dynamic range of the measurements. Therefore, if one is interested in the dynamic behavior of chemically conserved particulate matter (such as sulfate) in a short-term pollution event, more detail concerning the size distribution of the particles and the dynamics of the house are necessary to predict particle infiltration. However, long-term exposures to chemically conserved particles may be predicted successfully using population averaged physical loss factors and average data concerning house ventilation rates.

\section{Ammonium Nitrate}

Thus far, the analysis and discussion of the data have been performed using Eq. 2 as the governing equation for the system, which contains the important assumption that particles are chemically conserved. This is not the case with ammonium nitrate. Ammonium nitrate is a chemically reactive species, and its indoor concentration will depend upon conditions such as temperature, relative humidity, and gas concentrations inside the residence. Therefore, the phase change term in Eq. 1 cannot be neglected. The indoor/outdoor ratio of particulate nitrate was measured at much lower levels than either the sulfate or carbon. The reason for this behavior is the shift in equilibrium toward the gas phase as the nitrate enters the house. Ammonium nitrate is volatile, and the gas-toparticle partitioning is dependent upon the temperature, relative humidity, and the gas phase concentrations of ammonia and nitric acid (37). Figure 7 shows the nitrate indoor/outdoor ratio measured at 10-minute time resolution as a function of air change and indoor temperature. Examination of the plots reveals that the nitrate ratio is always less than one, and usually significantly so. Fig. 7a shows no progressive trend between the indoor/outdoor ratio and air change rate. Instead, data points appear to cluster in areas of the graph. The indoor/outdoor ratio plotted as a function of temperature, Fig. 7b, also exhibits no pattern. Instead, the indoor/outdoor ratio is quite small, primarily less than 0.2 , over a large range of indoor temperatures. 

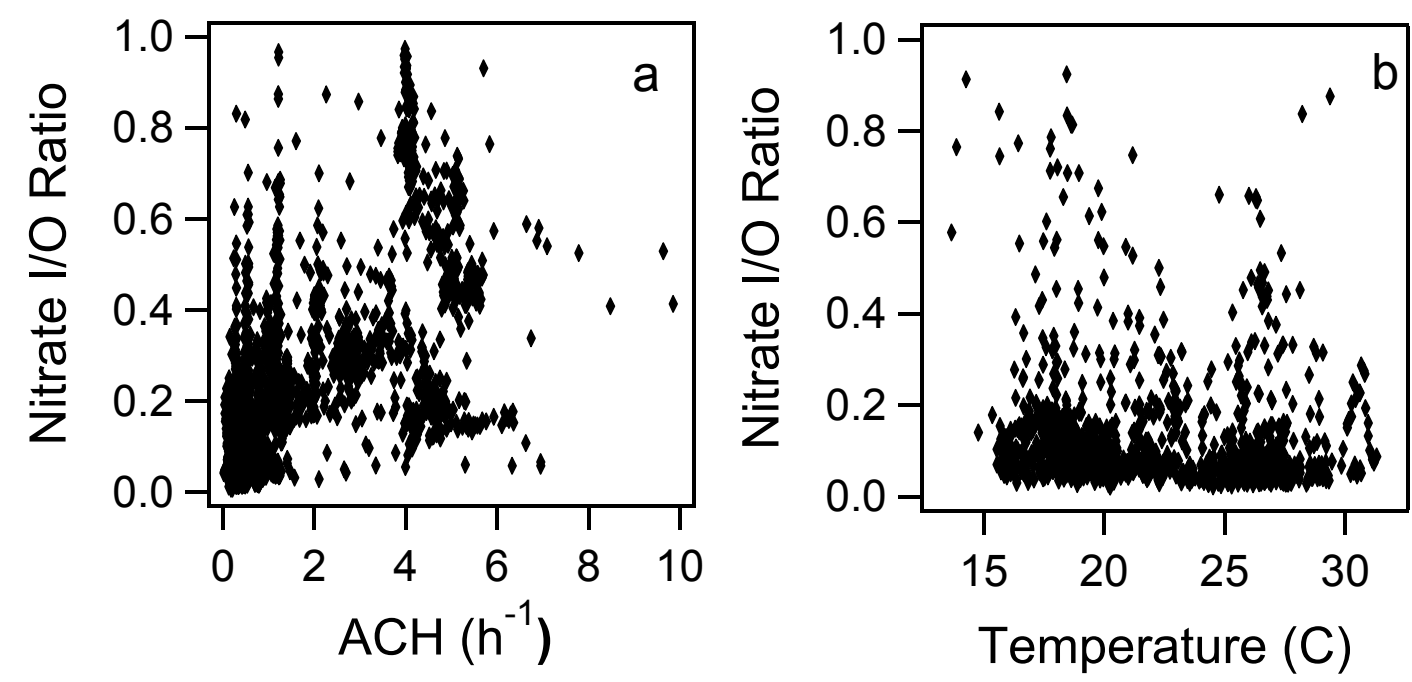

Figure 7. Nitrate indoor/outdoor ratio as a function of (a) infiltration rate and (b) indoor temperature. The data shown are hourly averages.

Previous experimental investigations have demonstrated that ammonium nitrate aerosol undergoes phase transitions during transport into and within houses (38). During the winter measurement period, the aerosol was moving from a cooler outdoor to warmer indoor environment, shifting the equilibrium of the nitrate formation reaction,

$$
\mathrm{HNO}_{3}(\mathrm{~g})+\mathrm{NH}_{3}(\mathrm{~g})<-->\mathrm{NH}_{4} \mathrm{NO}_{3}(\mathrm{a})
$$

to the left toward the gas phase. The gasses rapidly diffuse toward and absorb to surfaces inside the house, further driving the equilibrium toward the gas phase. Results of the gas phase measurement of ammonia $\left(\mathrm{NH}_{3}\right)$ and nitric acid $\left(\mathrm{HNO}_{3}\right)$ inside the house show a large amount of persistent ammonia with low to undetectable levels of nitric acid. After dissociation, the nitric acid gas is sorbing to the walls at faster rates than ammonia. We speculate that this is due to acid-base chemistry causing the nitric acid to be more tightly bound to the walls. This loss of nitric acid serves to continue to shift the equilibrium designated by Eq. 7 toward the gas phase.

The fate of ammonium nitrate inside the residence is a complex function of ventilation rate, temperature, and gas phase concentrations. The interaction among two of these variables can be observed in Fig. 8, a contour plot of the indoor/outdoor ratio of nitrate as a function of indoor temperature and infiltration rate. The conditions that resulted in elevated indoor nitrate levels are evident as lighter regions on the plot. A fall "open" condition is located in the upper left portion of the graph. In this case, the indoor and 
outdoor environments were almost equivalent because the air change rates in the house were relatively large, windows and doors were open, and the only significant particulate loss mechanism was deposition. An elevated winter condition is indicated in the lower center of the graph. In this case, the air change rates in the house were high, and the temperature was low. This large infiltration rate serves to constantly replenish the ammonium nitrate lost to dissociation, and the dissociation rate is reduced due to the low temperatures. The elevated condition in the upper left part of the graph occurred immediately after this elevated winter condition, when the temperature in the house was elevated but ventilation rates remained large. This indicates that even at these higher temperatures, the replenishment due to high air change rates was sufficient to maintain elevated indoor nitrate concentrations. When the ventilation rate was decreased to naturally occurring values, the indoor nitrate levels declined immediately. The final location with elevated indoor/outdoor nitrate ratio is in the lower right of the plot. This location, with low air change rate and moderate temperature, resulted from a rapid decrease in outdoor concentrations followed by a rapid increase. At the lower ventilation rate, the residence does not quickly respond to the rapid decrease in outdoor concentration, resulting in a temporarily elevated indoor/outdoor ratio.

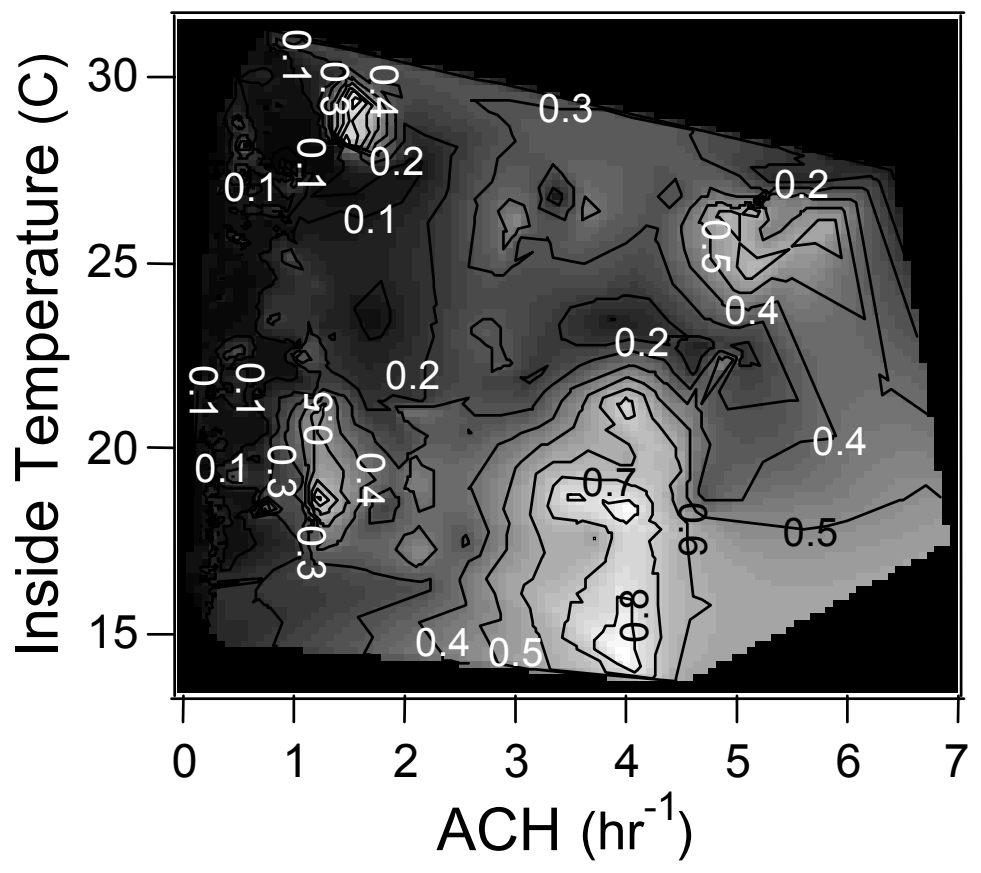

Figure 8. Contours of the nitrate indoor/outdoor ratio as a function of both indoor temperature and infiltration rate. 
The complex behavior of the nitrate aerosol indicates that chemical resolution of PM2.5 is crucial to understanding exposure to particles of outdoor origin. Traditional mass balance models for PM, like that shown in Eq. 2, cannot be applied to non-chemically resolved PM2.5 measurements. It is difficult to discern what proportion of time resolved measures of total particle mass or particle size distributions will be conserved species such as sulfate or chemically reactive species like nitrate. In addition, the highly timeresolved data show a wide range of indoor/outdoor ratios that might not be obvious in studies employing less time resolved measurements.

An important question is how generalizable these results are to other types of buildings, or to occupied spaces. The results concerning the affect of time-aggregation on indoor/outdoor ratios for conserved particles of outdoor origin would probably extend to other types of residences, since the behavior relies on fundamental physics regarding the important physical parameters in buildings. One caveat is that human interactions that resuspend outdoor particulate would have to be understood and incorporated. We believe that the transformation of outdoor ammonium nitrate is an important process that will occur in most buildings. Further study is required to allow for extension of these results to non-residential or multi-story buildings that primarily involve the dynamics of transport into and within the multiple zones that are present in these types of buildings. Moreover, more work is needed to characterize different temperature regimes (e.g. cooler indoors that outdoors) and building materials.

These results demonstrate the importance of knowing both particle chemistry and the real-time behavior of particle infiltration for understanding exposure to particles of outdoor origin. More importantly, the dissociation of the nitrate aerosol illustrates that an exposure assessment based on total particle mass measured outdoors may obscure the actual causal relationships to indoor particles of outdoor origin.

\section{Acknowledgements}

The authors dedicate this paper in memory of Dr. Joan M. Daisey, a treasured colleague who played a key role in the initial phases of this project, and whose vision has guided our work. This research was supported by the Assistant Secretary for Fossil Energy, Office of Natural Gas and Petroleum Technology, through the National Petroleum Technology Office under U.S. Department of Energy Contract No. DE-AC03-76SF00098 
and the Western States Petroleum Association. The authors thank Drs. Phillip Price, Marc Fischer, Richard Sextro, and Steven Ziman and Professor William Nazaroff for their helpful comments.

\section{Literature Cited}

(1) Dockery D.W.; Pope C.A.; Xu X.P.; Spengler, J.D.; Ware, J.H.; Fay, M.E.; Ferris, B.G.; Speizer, F.E. New England Journal of Medicine 1993 329, 1753.

(2) Pope C.A.; Bates D.V.; and Raizenne M.E. Environ. Health Perspect. 1995 103, 472.

(3) Krewski, D.; Burnett, R.T.; Goldberg, M.S.; et al. Reanalysis of the Harvard Six Cities Study and the American Cancer Society Study of Particulate Air Pollution and Mortality: Special Report. $\mathbf{2 0 0 0}$ Cambridge, Mass: Health Effects Institute.

(4) Pope, C.A.; Burnett, R.T.; Thun, M.J.; Calle, E.E.; Krewski, D.; Ito, K.; Thurston, G.D. J. Amer. Med. Assoc. 2002 287, 9.

(5) Research Priorities for Airborne Particulate Matter I: Immediate Priorities and a Long-Range Research Portfolio. National Academy Press, Washington D.C., 1998.

(6) Jenkins P.L.; Phillips T.J.; Mulberg E.J.; Hui, S.P. Atmos. Environ. 1992, 26A, 2141.

(7) Leaderer, B.P.; Cain, W.S.; Isseroff, R.; Berglund, L.G. 1984, 18, 99.

(8) Mosley, R.B.; Greenwell, D.J.; Sparks, L.E.; Guo, L.; Tucker, W.G.; Fortmann, R.; Whitfield, C. Aerosol Sci. Technol. 2001, 34, 127.

(9) Thatcher, T.L.; Lai, A.C.K.; Moreno-Jackson, R.; Sextro, R.G.; Nazaroff, W.W. 2002, Atmos. Environ. 36(11), 1811.

(10) Liu, D.L.; Nazaroff, W.W. Atmos. Environ. 2001, 35, 4451.

(11) Alzona, J.; Cohen, B.L.; Rudolph, H.; Jow, H.N.; Frohlinger, J.O. Atmos. Environ. 1979, 13, 55.

(12) Dockery, D.W.; Spengler, J.D. Atmos. Environ. 1981, 15, 335.

(13) Koutrakis, P.; Briggs, S.L.K.; Leaderer, B.P. Environ. Sci. Technol. 1992, 26, 521.

(14) Özkaynak, H.; Xue, J.; Spengler, J.; Wallace, L.; Pellizzari, E.; Jenkins, P. J. Exp. Anal. Environ. Epidemiol. 1996, 6, 57.

(15) Thatcher, T.L.; Layton, D.W. Atmos. Environ. 1995, 29, 1487.

(16) Abt, E.; Suh, H.; Catalano, P.; Koutrakis, P. Environ. Sci. Technol. 2000, 34, 3579.

(17) Vette, A.F.; Rea, A.W.; Lawless, P.A.; Rodes, C.A.; Evans, G.; Highsmith, V.R.;

Sheldon, L. Aerosol Sci. Technol. 2001, 34, 118.

(18) Long, C.M; Suh, H.H.; Catalano, P.J.; Koutrakis, P. Environ. Sci. Technol. 2001, $35,2089$.

(19) Nazaroff, W.W.; Cass, G.R. Envir. Sci. Technol. 1989, 23, 157. 
(20) Ligocki, M.P., Salmon, L.G., Fall, T., Jones, M.C., Nazaroff, W.W., Cass, G.R. Atmos. Environ. 1993, 27A, 697.

(21) Hansen, A.D.A.; Rosen, H.; Novakov, T. Sci. Total Environ. 1984, 36, 191.

(22) Stolzenburg M.R.; and Hering S.V. Environ. Sci. Technol. 2000, 34, 907.

(23) Fischer, M.L., Littlejohn, D., Lunden, M.M., and Brown, N.J. Environmental Science and Technology, in press.

(24) Kirchstetter, T.W.; Corrigan, C.E.; Novakov, T. Atmos. Environ. 2001, 35, 1663.

(25) Turpin, B.J.; Huntzicker, J.J.; and Hering, S.V. Atmos. Environ. 1994, 28, 3061.

(26) Forrest, J., Tanner, R.L., Spandau, D., D;Ottavio, T., Newman, L. Atmos. Environ. 1980, 14, 137-144.

(27) Anlauf, K.G., MacTavish, D.C., Wiebe, H.A., Schiff, H.I., Mackay, G.I. Atmos.

Environ. 1988, 22(8), 1589

(28) John W. and Reischl G. J. Air Pollution Control Assoc. 1980, 30, 872.

(29) Novakov, T., 1982. Soot in the atmosphere. In: Wolff, G.T., Klimish, R.L. (Eds.),

Particulate Carbon: Atmospheric Life Cycle. Plenum, New York, pp. 19-41.

(30) Novakov, T., 1981. Microchemical characterization of aerosols. In: Malissa, H., Grasserbaure, M., Belcher, R. (Eds.), Nature, Aim and Methods of Microchemistry. Springer-Verlag, New York, pp. 141-165.

(31) Sherman M. H., Dickerhoff D J. ASHRAE Trans. 1998, 104, part 2, 1359.

(32) Seinfeld, J.H., Pandis, S.N. 1998. Atmospheric Chemistry and Physics, John Wiley and Sons, Inc., New York, p. 817.

(33) Brauer, M., Hirtle, R., Lang, B, Ott, W. 2000. J. Exposure Analysis and Environ. Epidemiology, 10, 136.

(34) Riley, W.J., McKone, T.E., Lai, A.C.K., Nazaroff, W.W. 2002, Environ. Sci. Tech., $36(2), 200$.

(35) Thatcher, T.L., Lunden, M.M. Revzan, K.L., Sextro, R.G., Brown, N.J. Aerosol Science and Technology, in press.

(36) Thatcher, T.L., Lunden, M.M., Sextro, R.G., Hering, S.V., Brown, N.J. 2002. The effect of penetration factor, deposition, and environmental factors on the concentration of PM2.5 sulfate, nitrate and carbon indoors. Proceedings of the 9th International Conference on Indoor Air Quality and Climate, 2002.

(37) Stelson, A.W. and Seinfeld, J.H. Atmos. Environ. 1982, 16(5), 983.

(38) Hering, SV and Avol E. 1996. Indoor-outdoor concentration ratios for fine particle mass and inorganic ions in twelve southern California homes. In Proceedings of the Second Colloquium on Particulate Air Pollution and Human Health (Park City, Utah, May 1-3, 1996) pp.3-52. 
One sentence synopsis: A rich chemically- and time-resolved data set is used to investigate the affect of data aggregation and chemical speciation on dynamics of particle transport and fate indoors. 